\title{
Increased density of honeybee colonies affects foraging bumblebees*
}

\author{
Kerstin WAlther-HellWig, Gerriet FoKul, Robert FRANKL, Ralph BÜCHLER, \\ Klemens EKSCHMITT, Volkmar WOLTERS
}

Apidologie 37 (2006) 517-532

An error has been made in the above paper. The second author's name was misspelled. It should have been written "Fokuhl" instead of "Fokul". 